\title{
A Comparative Analysis of Education in Ghana and Cuba: Identifying Relevant Education Reforms for Developing Countries
}

\author{
Jordan Hale \\ Centre College, United States of America
}

\begin{abstract}
Centuries after the Industrial Revolution, most countries across the world today are still considered to be "developing." One of the reasons these developing countries fail to become "developed" is that their struggling education systems cause a lack of human capital. Consequently, the problem arises of how to improve developing countries' education, and thus help accelerate their development. Fortunately, my research in Ghana and Cuba has allowed me to identify several local and modern solutions to developing countries' education problems: expanding the education systems, improving learning quality, improving teaching quality, lowering costs, and providing resources. Ultimately, my research contributes to both education and development studies by identifying relevant education reforms for developing countries.
\end{abstract}

\section{Introduction}

Education plays a strong role in development, as it is essential to forming the human capital required for countries to develop. Human capital includes all of the skills and knowledge that workers use to increase workplace productivity, thus boosting the economy. Although the growth of human capital can only make a significant difference in development if the economy is sound and there are available jobs, it can still independently promote growth in the longrun by inspiring innovation among the citizenry, motivating entrepreneurs who then create the jobs and new technology that employ the available labor and grow the economy, resulting in a positive cycle of development. While there are many ways to promote economic development, "the concurrent growth and diffusion of human capital appear to be necessary to insure sustained economic development" [1].

Notably, increasing human capital has a larger impact on development than increasing physical capital (such as machines) because "indexes of human capital, such as average levels of education, are more strongly correlated with average income levels across countries than measures of physical capital per unit of labor" [1]. In fact, human capital growth is particularly relevant to developing countries, as many of them currently have more physical capital than human capital, meaning the rate of return for investments in human capital is much higher in developing countries than investments in physical capital [1].

Although education's role in GDP growth is important, there are other aims of development in which education also plays a role. As argued by some scholars - such as Nobel prize-winning economist Amartya Sen-the ultimate goal of development is freedom, not simple capital accumulation. GDP growth is seen as a mere means of achieving greater freedom [2]. In this goal, education is also critical, as it enables people to think individually and even to fight for their freedoms. Furthermore, education contributes to various other aspects of development, such as enabling informed and responsible citizenship, communication skills, lawful behavior, and better standards of health [1].

Indeed, development is a complex and multifaceted aim, and education plays a role in so much more than solely raising real per capita GDP; it empowers individuals living in developing countries to work towards and ultimately achieve their own country's development, both economically and politically, from the inside. Truly, better education is necessary in order to develop countries in the most wide-ranging and sustainable way.

\section{Literature review}

\subsection{Human capital}

Undoubtedly, education plays an important role in economic development. Education is the main source of income today in many developing countries, including Ghana [3]. As can be seen in the graph (see Figure 1) on the next page, GDP per capita (income) in Ghana decreased following Ghana's independence in 1957 from Great Britain, as Ghana had to work for many years to become a stable independent state. However, around 1980, the GDP per capita stopped decreasing and instead began to increase at a steady 
rate-reflecting the increase in human capital (education), which began to rise immediately following Ghana's independence as a result of Kwame Nkrumah's efforts to expand education. In other words, Ghana only reached sufficient levels of education to translate to economic growth within the last few decades. Eventually, this improved access to education translated to a more productive workforce, which helps account for the eventual reversal of Ghana's economic downturn.

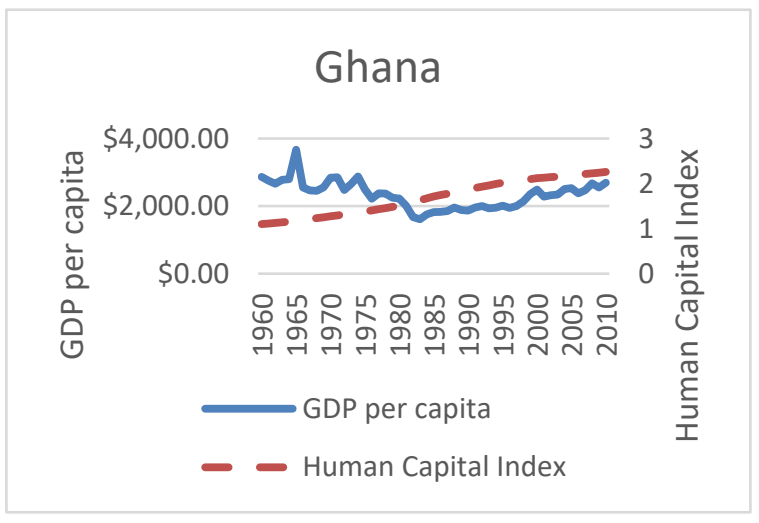

Figure 1. Human capital and GDP growth in Ghana

This graph demonstrates a significant correlation between human capital growth and GDP per capita growth in Ghana starting around 1980.

The Human Capital Index measurement graphed above was created by the Penn World Tables and represents the average years of schooling (based on data collected by Barro and Lee) combined with an assumed rate of return to education (based on Mincer equation estimates for each country). Therefore, this measurement reflects both educational quality and access in Ghana, and how this education actually translated to increased human capital and thus productivity and economic growth [4].

\subsection{Economic growth}

To isolate the impact of growth in human capital per worker on GDP per capita growth in Ghana, I conducted a simple growth accounting exercise (using data from the Penn World Tables and Barro and Lee [2010]) to break down Ghana's observed per capita GDP growth rate into its constituent factors: physical capital accumulation, human capital accumulation, and total factor productivity. Growth accounting is based on the augmented Solow model, which says GDP is produced using three distinct inputs: physical capital, human capital, and labor. The growth in GDP can be attributed to the growth in these factors, accounting for their share $(\alpha, \beta, 1-\alpha-$ $\beta$ ) in GDP. The part of the growth not explained by the growth in these factors is termed Solow residual (gA), or total factor productivity, which captures growth in the many other factors that affect GDP growth, encompassing mainly technology development. Since I was looking at per capita growth, I divided each input by the size of the labor force, which is why labor is no longer part of the equation.

Ultimately, education should increase both growth in human capital per worker (gh) and total factor productivity (gA). Improving the quality of education creates growth in innovation and thus total factor productivity, which leads to long-run economic growth. Meanwhile, increasing access to education leads to growth in human capital which, like all forms of capital, exhibits diminishing returns, meaning that solely increasing access to education (without improving quality) does not lead to long-run economic growth.

The growth accounting equation is given as:

$$
g y=g A+\alpha g k+\beta g h
$$

where, gy is the average annualized growth rate of per capita GDP; gk, average annualized growth rate in physical capital per worker; gh, average annualized growth rate in human capital per worker; and gA, average annualized growth rate in all other factors (total factor productivity); describe the variables. The share of each input-represented by $\alpha$ and $\beta$-is set at a constant proportion of $1 / 3$ (as assumed by Mankiw, Romer, and Weil). Thus, I was able to calculate the impact of growth in human capital per worker (gh) and total factor productivity per worker (gA) on the average annualized growth rate of per capita GDP (gy).

I define human capital as the number of people in Ghana with at least a secondary school education. To use as my value for human capital, I referenced Barro and Lee's data on the number of people aged 15 and above in Ghana with access to at least a secondary education, first in the year 1960 and then the year 2010, and plugged these values (divided by the size of the labor force) into the average annualized growth rate formula to get the average annualized growth rate in human capital per worker for Ghana. Using this measure, the equation above allows me to isolate the impact of total factor productivity growth as follows:

$\mathrm{gy}=\mathrm{gA}+\alpha \mathrm{gk}+\beta \mathrm{gh}$

$0.0023=\mathrm{gA}+(1 / 3)(0.001)+(1 / 3)(0.069)$

$0.0023=-0.021+0.0003+0.023$

This equation shows that in Ghana, there has been $0.23 \%$ annualized average growth in GDP per capita between 1960 and 2010, most of which has come from the $2.3 \%$ annual growth in human capital per worker. This impressive growth in human capital is primarily due to the fact that Ghana had almost no students $(2.4 \%)$ with access to secondary school in 
1960, while fifty years later, the percentage of students who had access to secondary school $(57.8 \%)$-although still low-was much higher than it was before. However, Ghana's access to education today, although relatively higher, is still too low in absolute numbers to translate to significant economic growth.

After human capital, Ghana's $0.03 \%$ growth in physical capital per worker accounts for the second highest proportion of Ghana's economic growth. Finally, growth in all other factors not accounted for is $-2.1 \%$ for Ghana, due to a lack of technology development. This explains Ghana's nearly-stagnant GDP per capita growth over the fifty years from 1960 to 2010, and suggests that improved access to education in Ghana is not translating to innovation and technology development.

Therefore, this paper will focus on improving both the access to and quality of education in Ghana and other developing countries, since improved access alone is not generating either significant technology development or significant economic growth. Since growth in school enrollment without a subsequent growth in the number of resources and schools available can lead to diminishing educational quality (through expanding class sizes), developing countries must be careful to first implement necessary policies (such as increasing funding for schools) to ensure that increasing access to education does not diminish the quality of education. In this way, developing countries can grow both in the short term-by increasing educational access, and thus human capital — and in the long term - by increasing educational quality, and thus total factor productivity.

\subsection{Education in Ghana and Cuba}

The quality of and access to education in developing countries - although generally low-can vary significantly. For example, in Cuba $(\$ 10,200$ GDP per capita), the education system is free for all and ranked among the highest in the world; while in Ghana (\$4,300 GDP per capita), the education system is prohibitively expensive and poorly ranked [5]. Ghana's ineffective education system ultimately slows the country's rate of development. Fortunately, Cuba's remarkable success in education offers key insights that can be used to improve education in other developing countries, such as Ghana.

Both access to and quality of education in Cuba are highly-ranked today due to Fidel Castro's efforts to provide universal and high-quality education following the Cuban Revolution-particularly through his nationwide literacy campaign. As a result, Cuba's current literacy rate and exam scores are more similar to those of developed countries than to those of other developing countries. For instance, Cuba's literacy rate is among the highest in the world at $99.8 \%$, and the country ranks first in the world for math and language in its primary schools. Additionally, access to education is high in Cuba, with $94 \%$ of Cuban children attending pre-K, $100 \%$ of students reaching the sixth grade, and $99 \%$ of students reaching the ninth grade [6].

Interestingly, Cuba is now sending many of its own graduates to Ghana and other developing countries, to provide necessary services and to promote education and thus development in those countries as well. Cuba then receives money from these developing countries in return for the services rendered by the Cuban graduates. As a result, education is considered the most successful export of Cuban Socialism [7]. For example, Cuba's Latin American School of Medicine trains doctors to serve in more than twenty developing countries [6]. Ultimately, Cuba sends over 35,000 medical workers to these countries [7].

Ghana, one of the recipients of these highlytrained Cuban graduates, has an education system that lacks both easily-accessible and high quality education. Consequently, over half of basic education graduates in Ghana are functionally illiterate and innumerate, and only $76.6 \%$ of the total Ghanaian population is literate [8]. Furthermore, only $86.6 \%$ of Ghanaian children enroll in primary school, 50\% attend junior high school (lower secondary school), and $33 \%$ are admitted to senior high school (upper secondary school) [3].

Fortunately, the Ghanaian state recognizes the need to improve its education. Ghana's Forum for Education Reform has declared, "Ghana's development discussion must elevate education to the highest rung, because of the strong nexus between education and development" [9]. Likewise, Ghana's Ministry of Education has emphasized the need "to provide relevant education to all Ghanaians at all levels to enable them to acquire skills that will assist them to develop their potential in order to be productive...to facilitate poverty reduction and to promote socio-economic growth and national development" [10].

\section{Methodology}

While Cuba's unique command economy prevents the country from fully capitalizing on its superior education in order to develop its economy, other developing countries with more open economies could accelerate their own development by adopting elements of Cuba's successful approach to education and thus increasing their human capital. Using data collected from interviews and observations I conducted in Ghana and Cuba in 2017, I outline in this paper critical education reforms for developing countries, based on my analysis of ineffective practices in Ghanaian schools and successful ones in Cuban schools. By comparing 
the data I collected in these two countries, I have identified the most needed reforms to enable developing countries to improve their education, and thus develop their economies. In particular, I hope to give developing countries more of a voice in their own education reform, by sharing the views and realities of the people living in these countries today, and in this way ensuring that the reforms I propose are relevant to both modern and local needs.

\section{Analysis of findings}

\subsection{Size of education system}

4.1.1. Number of schools. Countries should avoid having a shortage of schools and classrooms, as this shortage necessitates having large class sizes, which ultimately detracts from students' learning experience. Fortunately, Cuba maintains plenty of schools and classrooms for its population. Therefore, Cuba keeps class size maximums at manageable levels - around twenty to thirty students.

By contrast, Ghana lacks enough schools and classrooms: there are currently many classrooms in Ghana with over one hundred students in each. However, since building more schools can be expensive, one Ghanaian suggested that teachers be sent out to teach those who have little access to education, primarily in rural areas. This is similar to Cuba's Literacy Campaign in the early 1960s, in which the state sent out thousands of graduates to teach illiterate Cubans how to read and write.

In addition, it is important to offer a variety of schools for the variety of people within each country. For this reason, Cuba supports a variety of schools. Although all schools in Cuba are public-from preschool to university-there are many types of schools offered, including technical and vocational schools. One vocational school I visited specialized in teaching its students how to restore old buildings and artifacts. Students at this school actually received a salary while studying and practicing their art. Vocational schools in Cuba can be very competitive, with only $20 \%$ of applicants accepted to the restoration school I visited. This is because, upon graduating, students are guaranteed a job with the government.

Additionally, vocational schools in Cuba only take two years, with one semester spent learning theory, and the other three spent practicing. As a result, two-thirds of Cuban students choose vocational education instead of going on to preuniversity. The Cuban state is trying to encourage this shift by placing a quota on the number of students allowed to attend university [7]. One teacher I interviewed in Cuba passionately advocated for vocational education, especially in developing countries, saying that it provides the skilled, blue- collar workers that are desperately needed in these countries.

For a similar reason, Ghanaians suggested offering more nontraditional schooling options, including adult education, special education, and vocational schools. Currently, most schools in Ghana only offer traditional liberal arts. Ghana does offer technical and vocational schools, but many of these are under-resourced and have poor reputations, resulting in a lack of skilled blue-collar workers in Ghana. There are also some specialty schools offered in Ghana-such as one school I visited which focused solely on training students to enter the catering business - but they are not common and are poorly-funded.

By expanding the number of schools or by sending teachers to areas without schools, developing countries could increase access to education for many students. Specifically, adding more vocational schools would help developing countries provide more relevant education, since most jobs in developing countries' economies require mainly vocational training.

4.1.2. Time in school. The amount of time students spend in school is critical, as it determines whether or not they are able to cover all of the necessary curriculum. In Cuba, students attend primary school for seven years (preschool through sixth grade) and basic secondary for three years (seventh through ninth grade). In all, basic education is ten years in Cuba. By contrast, in Ghana, primary school lasts for six years, and junior high school lasts three years. In all, basic education is only nine years in Ghana [11].

After ninth grade, students in Cuba choose between either attending pre-university for four years or technical school for two years at the upper secondary level [11]. This means pre-university education in Cuba lasts a total of fourteen years. Upon graduating upper secondary, Cuban students can choose to attend five years of undergraduate school. Afterwards, they must do social service as assigned by the Cuban state - two years for boys, since they are also made to do one year of military service, and three years for girls.

Conversely, all Ghanaian students who continue their education attend senior high school for another three years [11]. In all, pre-university education in Ghana has been shortened from fifteen to twelve years in order to ease the financial burden on parents, although many complain this is not enough time to cover the required curriculum. Thus, Ghanaians recommended expanding senior high school to four years - as it was briefly, with positive results. Finally, tertiary education in Ghana (university, training institutes, specialized institutes, or polytechnics) takes four years, and no service is required of students. 
Overall, Ghanaian students are not in school long enough to cover the required curriculum. Critically, the amount of time students spend in school affects their scholastic performance, and-ultimately-their ability to find a job following graduation. For this reason, Ghanaian students said they wanted to learn more. Likewise, a few teachers in Ghana told me, "There is too much in the curriculum. There's not enough time to cover it all. We need more time."

One solution to the insufficient time many students in developing countries spend in school is to allow students to specialize in certain subjects or fields of study, so that they can cover all of the necessary material and focus only on the subjects they will actually use in their future careers. In Cuba, students are placed on a specific path early in their schooling so they can focus primarily on the specialized topics in their assigned career field. Unfortunately, Ghana does not allow such specialization in its schools.

Increasing the amount of time students in developing countries spend in school, or allowing them to specialize in a particular field, would make it possible for students to cover all of the necessary curriculum, and thus gain more from their schooling.

\subsection{Learning quality}

4.2.1. Curriculum. Educational curriculum ought to be relevant to both the modern and local needs of each country, to ensure that students learn the skills desired by employers. Cuban students learn a distinctly Cuban curriculum that has been approved by the state and which promotes the states' values: in this way, Cuban education is more relevant to Cuban realities. As a result, unemployment in Cuba is remarkably low. Specifically, general education and basic studies in Cuba include politics, PE, Cuban history, Spanish literature, physics, history, computing, English, math, chemistry, basic sciences, and civic education. Vocational education can also be found throughout the levels of Cuban education and includes sewing, wood, plastic and metal work, cooking, and gardening in primary school, as well as job skills, work with materials, agriculture, electricity, and textiles in basic secondary [12].

By contrast, the curriculum in Ghana is irrelevant and outdated. Many teachers felt that the curriculum was not relevant, saying that the traditional British subjects-English, Math, Social Studies, Science, French, Dictation, Drawing, Environment, and Moral Education-are not practical in modern-day Ghana. As a result of this irrelevant curriculum, graduates suffer from unemployment due to a lack of skills, or human capital. Instead, students want to be taught employable skills. Ghanaian students especially expressed interest in more math and science classes.
Another result of this colonial influence is that instruction in Ghanaian schools is only offered in English or French, even though most students can only speak a few basic English or French phrases. As a result, many students are not confident in their ability to speak these languages, and thus do not contribute or understand nearly as much in class.

A Ghanaian mother I spoke to described the curriculum: "One thing in our education, you know when you learn, maybe you go to university, you learn the technical, but when you leave, you don't have the facilities needed. You learn something else about like a Greek. It's not practical. They will be there for the four years but when they come out, they don't have anything to do. They have to go out, up and down, looking for jobs. [After] they are in school...the nation needs to help. Graduates have nothing to do."

This irrelevance could stem partially from policies that are made in Accra but do not reflect the realities in the villages. Notably, a Ghanaian administrator told me that Ghana needs to stop relying so much on outside aid to support its schools, because the countries providing aid often require that Ghana implement certain educational policies that can be irrelevant and actually harmful to Ghana's education.

Finally, it is important that the curriculum is focused enough so that it can realistically be covered in the time students are in school. Thus, Cuban curriculum is condensed into a manageable amount so that teachers can cover it more thoroughly. On the other hand, many people I spoke with in Ghana felt that the curriculum tried to incorporate too many topics, and thus inadequately covered each subject. The Ghanaian curriculum tends to be very basic and generalized, and lacks specific foci or specializations that could be useful. Such a packed curriculum means that missing even one class can seriously harm a student's understanding of the material.

Adopting a more relevant and condensed curriculum in developing countries could help address high youth unemployment in those countries, and in this way promote economic growth. In particular, developing countries could provide more relevant education by taking control of their own education reforms and practices.

4.2.2. Teaching methods. For education quality to be high, teachers must maintain control of their classrooms. Cuban classrooms are very efficient, and little time is lost in transitions or interruptions. The level of focus in Cuban classrooms rivals that of developed countries [13]. This is because teachers and students in Cuba form a bond and are constantly learning from each other and interacting with each other. Students even elect a "student representative" from among the teachers: this teacher is elected to 
speak for the students, thus serving as their representative.

Furthermore, schools in Cuba supervise their students to make sure they can succeed. For example, to promote the development of lasting relationships between teachers and students, primary teachers in Cuba stay with their students for the first four years. This will soon be expanded to six years (first through sixth grade). Additionally, at lunch, Cuban students eat in a common room with their teachers, so they can grow comfortable around each other and form deeper relationships. These policies try to provide greater teacher responsibility for student success, and help teachers get to know their students better.

Schools in Cuba also keep track of family difficulties, and families must respond to school concerns. To help reduce absenteeism, when children are sick, the teacher stops by the house after a day or two to check up on the child [13]. When describing how she looks out for her students, one Cuban teacher said, "It's not that it's mandatory by law, but we feel personally obliged to help them. Even if, you know, they have stopped being your student for ten years, you see them on the street and you have this feeling, this connection that you feel involved in their life, part of their life, and to get involved. It has happened to me; I have seen my students or former students in trouble and I have helped them."

In sharp contrast to the amicable discipline maintained in Cuban classrooms, corporal punishment-mainly caning-is still used in Ghanaian classrooms. Misbehaving students are punished to set an example. Although discipline is emphasized in Ghanaian schools as the key to student success, it fails to increase focus in the classroom. When I was observing classrooms, I saw many undisciplined outbursts during the long structured and unstructured free time in the school day; students often have multiple scheduled breaks each day as well as long transition-periods between classes. Overall, learning activities in Ghana only take up $39 \%$ of class time, while around the world the average is $71 \%$ [14].

Beyond simply maintaining control of students, teachers should try to use student-directed teaching methods, as recent pedagogy suggests that students learn more if they are involved in lessonsinteracting with the teacher and employing critical thinking. Teachers in Cuba are trained to teach using these student-directed teaching methods, in order to facilitate better understanding among their students.

Meanwhile, in Ghana, teaching-like the curriculum - is very traditional. Students are simply expected to copy notes and regurgitate information in class, and there is very little interaction or critical thinking required. Ghanaian students often only interact with teachers and receive feedback when taking tests. This rote-style of learning comes from traditional Western teaching methods introduced by Great Britain.

Using more student-directed teaching methods would allow developing countries to improve the quality of their education systems. Additionally, supervising students and forming personal relationships with them could also facilitate better education.

\subsection{Teaching quality}

From the start, teaching could be improved through better training. Cuban teachers are competent due to their superior training. Generally, in their first year of training, pedagogical students in Cuba spend one month observing and working in schools, and the rest of the time studying pedagogy. In their second year, trainees teach in schools two days a week, and three days a week in their third year. In their fourth and fifth years, trainees work in the schools five days out of the week, and then go to pedagogical school one additional day. As one Cuban teacher said about teacher training, "so we had to go be real workers, real teachers, even when we were still studying the career." Due to good training, teachers feel competent to deliver Cuba's well-defined national curriculum.

Meanwhile, teacher training in Ghana is poor. In Ghana, many teachers do not even go to college, particularly primary teachers. For example, nursery teachers can simply attend nursey training courses for only six months before teaching. A Ghanaian student summarized teacher training in Ghana by saying: "The teachers are usually polytechnic graduates but I know a couple of high school graduates who are teachers in basic schools."

Once teachers are already in the classroom, the state can ensure effective practices through employing constructive supervision. As a result, the Cuban state oversees teachers in order to improve classroom practice. Teachers are closely supervised by administrators, who are required by the state to directly observe and assist teachers. Cuban teachers are supervised weekly and receive immediate feedback. They are also expected to come into the schools six days a week including Saturdays, to prepare their lessons for the next week, and are thus paid a living wage in order to eliminate the need to hold a second job.

By contrast, Ghanaian teachers are not held accountable and are thus allowed to fall behind on their work. As a result, teachers in Ghana often relax instead of teach, are preoccupied by something-like their own children, who they sometimes bring to school-or do not even show up. Ultimately, Ghanaian teachers are absent or late more than $40 \%$ of the time [14]. Furthermore, since the teachers who do show up are often preoccupied and not focused on 
teaching, instruction is relaxed. Even during lectures, many students wander around, sleep, or play with other things while the teacher is teaching. Still, administrators in Ghana do little to monitor teachers. When asked how he is supervised in his classroom, one teacher told me, "I supervise myself."

Overall, most Ghanaian teachers simply discipline their students by caning them, do not bother to ask their students questions or collect and grade school assignments, and are often late, absent, or not in the classroom. Thus, the Ghanaian teachers I spoke to expressed a desire to improve teaching by ensuring that their colleagues punish students with corrections rather than corporal punishment so that students can learn from this positive formative feedback; that teachers ask students questions to make sure they understand their work and collect and grade all assignments to both motivate students and show them what they need to work on; and that teachers try to always be among their students during the school day. In other words, they wanted to guarantee that teachers monitored students better.

It is worth noting that many teachers and administrators in Ghana are set up to fail, as they are provided with little money and time. Teachers lack teaching materials, and are thus required to provide or make their own, but many cannot. This is because many teachers in Ghana must take second jobs in order to make a living wage, so they have less time to prepare classes and help students [3].

Instituting better teacher training, raising teacher salaries, and providing teachers with more resources would enable teachers in developing countries to improve learning in their classrooms. Additionally, increasing supervision of teachers would hold them accountable and help them be more effective teachers.

\subsection{Cost of education}

4.4.1. School fees. In order to provide free education to all students in the often densely-populated developing countries, education budgets must be increased. Although Cuba and Ghana are both already very invested in their education systemsranking in the top fifteen countries in the world for the percentage of their GDP dedicated to education - Cuba still spends over twice as much on education as Ghana does, despite its much smaller population [8]. Overall, $12.8 \%$ of Cuba's $\$ 132$ billion GDP goes towards education (over \$16 billion), which is the second highest percentage in the world, following only Lesotho. As a result, in 2010 , approximately $\$ 2,799$ was spent on each Cuban primary student, $\$ 2,958$ on secondary students, and $\$ 3,575$ on tertiary students [15].

Because of its manageable population of 11 million - an average of one and a half children per family, $15.96 \%$ of the population between ages 0-14 and $13.29 \%$ between ages $15-24$, and a median age of 40.4 years - the Cuban state can provide free education to all Cubans [8]. Parents I spoke to in Cuba stated that they were made to pay only small school fees to cover students' lunches, in addition to buying the required school uniforms. Indeed, all schools in Cuba are public - with no school fees-as the state fully funds education, offering free education from the primary level to university for all students. In this way, the Cuban state ensures that every student has access to school.

Conversely, Ghana's reduction in and misuse of education funding have led to large school fees juxtaposed with few scholarships across the entire country. Therefore, although education in Ghana is free in name, it is not free in reality. Students are made to pay large school fees, even in public schools, which restricts access to education. The Ghanaian government still claims that it provides free education, and so many parents become confused and do not bother to buy their children necessary textbooks, thinking the schools will provide them. Therefore, Ghanaians suggested that the state stop falsely claiming to provide free education and instead raise and reallocate funding, in order to lower school and textbook costs.

These insufficient funds also stem from the fact that the large education budget in Ghana is not growing fast enough to handle Ghana's exponential population growth. Ghana has a population of 26 million, an average of four children per family, and has $38.38 \%$ of Ghanaians between $0-14$ years old and $18.69 \%$ between $15-24$ years old, resulting in a median age of only 20.9 years [8]. Due to Ghana's large youth population, there is a high demand for spots in schools. Despite the fact that $6 \%$ of Ghana's $\$ 115$ billion GDP goes to education (almost \$7 billion), which is the 13th highest percentage in the world, Ghana's education system still ranks among the worst in the world today [8]. Indeed, in 2013, the government of Ghana only spent approximately $\$ 174$ per primary student, sixteen times less than the Cuban government spends on its pupils [15].

Consequently, far too many expenses are placed on Ghanaian families. In Ghana, the state expects families to cover most costs. For example, the state requires close to ten expensive textbooks for each student but does not provide enough textbooks, thus requiring parents to pay extremely high textbook fees - often higher than school fees. To make matters worse, some schools even make parents pay for the school's water, heating, and basic maintenance by raising school fees to include these costs. Finally, since most students live at home, and since there is no form of public transportation for Ghanaian schools, students' families must also cover transportation costs. 
Overall, the education costs in Ghana are higher than many Ghanaians can afford. Annual school fees are around 900 cedis - about \$250-and to this parents must add textbook fees-which cost more, and so bring the total to around 2,000 cedis, or $\$ 500$. One Ghanaian I interviewed told me how these fees affect educational access when she said that "the government fees are very new, and it's costing [the students] their education."

Access to education in developing countries can only be truly universal if school fees are lowered or even eliminated.

4.4.2. Unequal access to schools. The high cost of education in some developing countries restricts access to education for all students, but especially for low-income students. However, in Cuba, there is little differentiation in the content level or task intensity of lessons taught to high and low-income students. The management system assures that the national curriculum is applied universally regardless of students' social class. Thus, in Cuba, students achieve at a much higher level than expected given their socioeconomic background and income per capita. For example, although $38 \%$ of Cuban schools are rural-composed of lower-income students with less-educated parents - there are few differences in student performance between these rural schools and other urban schools [13].

Ultimately, Cuba's education system ensures that all students can rise through the levels of school, regardless of gender, income, or race. In Cuba, access to school is guaranteed, even for those populations who are often excluded from education in other countries. Interestingly, in Cuba, women make up $80 \%$ of university students and $68 \%$ of graduates. As a result, women make up $66 \%$ of the labor force in Cuba: $70 \%$ of professionals, $69 \%$ of healthcare workers, $66 \%$ of lawyers and judges, $24 \%$ of engineers, and almost half of the members in the Cuban legislature are female [16].

On the contrary, Ghana's education system suffers from biased organization which only allows students with money to rise through the levels. Better schools are more expensive in Ghana, among both private and public schools. Thus, high-income students in Ghana are the only ones able to afford the best primary and lower secondary schools, and are thus able to score higher on competitive entrance exams to enter upper secondary schools and universities. Due to the high costs of good education in Ghana, there is an inequality in access largely based on the socioeconomic status of the student.

Focusing on increasing funding specifically for those students in developing countries who lack access to school due to large school fees-through means such as scholarships-could help address inequality in access to schools.

\subsection{Educational resources}

4.5.1. School materials. Students can only do well in school if they have access to the materials required to learn. Fortunately, schools in Cuba provide their students with all the resources they need. These schools get the materials from the Cuban state which, due to its high education budget, can provide schools with all necessary materials, at no cost to the schools or to the students. Thus, Cuban families only provide a few educational resources for their children, as almost everything is provided by the state. Every Cuban student has his or her own individual desk in the classroom. Moreover, all equipment that students use in their classrooms and labs-including textbooks, writing utensils, and scientific equipment - are provided by the schools.

Still, one of the primary recommendations offered by interviewees in both Cuba and Ghana was providing more school materials for students in developing countries, since Cuban studentsalthough they have access to all needed materialsoften must use older materials that are of poor quality, due to the United States' blockade. Ultimately, interviewees in the two countries identified this lack of [quality] resources in the homes and schools as the most substantial barrier to improving education in developing countries.

Worse still, classrooms and schools in Ghana do not even supply their students with enough resources. Ghanaian basic education schools provide an average of 0.6 math textbooks, 0.5 English textbooks, 0.5 science textbooks, 0.7 seats, and 0.7 desks per student [10]. Because of limited communal supplies, Ghanaian students are usually made to provide their own writing utensils, textbooks, and paper. In addition to lacking communal school resources, Ghanaian schools often lack necessary infrastructure. Most Ghanaian schools have a shortage of workshops and laboratories, and especially lack materials for vocational education [3]. Consequently, many Ghanaians suggested that schools and the state overall should provide resources like textbooks, water, heating, and lighting, as these costs currently rest on parents' shoulders (through school fees).

In addition to not having enough classrooms or schools in Ghana, those that do exist are often poorly constructed and too small, and thus very loud, dirty, and in poor condition. As one student told me, "In some villages, the students school under trees (so no school when it rains) and in others, some school in 'rickety' buildings. It's very pathetic."

Lastly, Ghanaians argued that both the government and the private sector should provide more resources. Several interviewees in Ghana even 
said that computers should be provided, because Ghanaians need to be prepared for the modern world. Computers could also enable students to access more learning materials. Other interviewees suggested that the media could provide educational resources, by creating learning programs for students. Still others said that people should send monetary aid to struggling families and communities, thus enabling children to have better home environments in which to focus on their studies and more money to use for school fees.

Providing school resources and infrastructure to students in developing countries would enable them to succeed in school and thus improve their jobhunting prospects following graduation.

4.5.2. Unequal access to materials. The lack of free school materials in some developing countries restricts access to these resources for all students, but especially for low-income students. However, in Cuba, all necessary materials are supplied for free by the state, and this enables all students to have access to education and to succeed while they are in the classroom. Cuban schools even offer free tutoring led by teachers for struggling students. Meanwhile, in Ghanaian schools, extra classes and tutoring are only available to those students who can afford them.

Furthermore, disadvantaged students not only require free materials in schools, but they also require additional assistance at home. For this reason, the Cuban state makes sure to provide support to those families which are struggling, to ensure that their children can go to school and do well in school. Therefore, all students in Cuba have access at home to the materials needed to succeed in school.

In Ghana, schools make no effort to accommodate for poor students' disadvantages. The poor conditions of low-income students' houses and communities in Ghana make it hard for them to focus on school. Many students' houses are crowded and noisy, since Ghanaians usually live in small houses with all their extended family.

Additionally, many students in Ghana have uneducated parents who are so busy working to make a living wage that they do not have time for their children, and do not have enough education to help their children with their studies even if they had the time. When asked if she thought her children had an equal opportunity to succeed as other students, a single mother in Ghana answered: "No. There's no money for them to push up. Their daddy's dead. They are not wealthy. We don't even have [a] home."

As these uneducated, poor parents often raise their children in poor neighborhoods where the children are surrounded by other uneducated families, there is an overall lack of focus on education in the communities in which poor students live. One teacher told me, "It's horrible. Because parents don't have time for their children. A regular Ghanaian family: the parents go to market, they don't have time for their children, they don't care. If your child is in such a community, they're not made to think. Most parents are illiterate. So what can the child do? The parents can't help them."

To ensure students have an equal opportunity to succeed in the classroom, developing countries could specifically target aid to those students who lack access to educational resources both at school and at home.

\section{Conclusion}

Undoubtedly, the solution to developing countries' education problems is not simple and would involve substantial financial investment on the part of these developing countries, but the policy recommendations I have described identify key areas within developing countries' education systems that must be improved if better education-and thus development - in these countries is to be realized.

\section{References}

1. Mincer, Jacob (1981) 'Human Capital and Economic Growth,' National Bureau of Economic Research, Cambridge MA.

2. Sen, Amartya (1999) Development as Freedom, Knopf, New York.

3. George J. Sefa (2004) Schooling \& Education in Africa: The Case of Ghana, Africa World Press, Trenton NJ.

4. Zeileis, Achim (2017) pwt9: Penn World Table (Version 9.x), R package version 9.0-0.

5. The World Bank (2017) 'GDP per capita (current US\$),' The World Bank; https://data.worldbank.org/ indicator/NY.GDP.PCAP.CD? end $=2010 \&$ start $=1960 \quad(2$ June 2017).

6. Cuba Diplomatica (2015) 'Education,' Cuba Diplomatica; http://www.cubadiplomatica.cu/eeuu/EN/ LearnaboutCuba/Education.aspx (2 June 2016).

7. Wolf, Stefan, Hernandez Penton, Filipe A., Marin, Anna Lidia Beltran, \& Romero, Osvaldo (2011) 'The Cuban Vocational Education and Training System and its Current Changes,' Journal for Critical Education Policy Studies, pp. 224-40.

8. Central Intelligence Agency (2016) 'The World Factbook,' CIA; https://www.cia.gov/library/ publications/the-world-factbook/ (11 May 2016).

9. Imani (2013) 'State of Education in Ghana,' The Forum for Education Reform; https://www.modernghana 
.com/news/509540/state-of-education-in-ghana.html May 2016)

10. Ministry of Education (2016) 'Ministry of Education,' Ministry of Education Ghana; http://www.moe.gov.gh/ (14 May 2016).

11. Class Base (2012) 'Education Database,' Class Base; http://www.classbase.com/Countries (26 May 2016).

12. CubaEduca (2016) 'CubaEduca'' CubaEduca; http://www.cubaeduca.cu/ (4 July 2016).

13. Carnoy, Martin (2007) Cuba's Academic Advantage: Why Students in Cuba Do Better In School, Stanford University Press, Stanford CA.

14. Del Mar, David Peterson (2013) 'Ghana,' International Guide to Student Achievement, pp. 465-7.

15. World Data Atlas (2017) 'Expenditures on Education,' World Data Atlas; https://knoema.com/atlas /Ghana/topics/Education/Expenditures-on-Education/ Expenditure-per-student-in-primary-education (2 May 2017).

16. AAUW (2011) 'Gender Equality and the Role of Women in Cuban Society, pp. 1-9; http://www.aauw.org/ files/2013/01/Cuba_whitepaper.pdf. 